JAOS

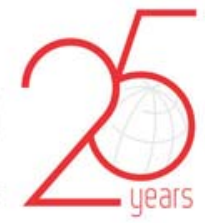

\title{
Role of Candida species from HIV infected children in enamel caries lesions: an in vitro study
}

\section{Abstract}

Senda CHARONE ${ }^{1,2}$

Maristela Barbosa PORTELA ${ }^{3}$

Karol de Oliveira MARTINS ${ }^{3}$

Rosangela Maria SOARES ${ }^{4}$

Gloria Fernanda CASTRO ${ }^{1}$

Submitted: February 12, 2016

Modification: September 19, 2016

Accepted: September 23, 2016
Objectives: This study analyzed the capacity of Candida spp. from dental biofilm of HIV infected (HIV+) children to demineralize primary molar enamel in vitro by Transversal Microhardness (TMH), Polarized Light Microscopy (PLM) and the quantity of calcium ions $\left(\mathrm{Ca}^{2+}\right)$ released from the enamel. Material and Methods: Candida spp. samples were isolated from the supragingival biofilm of HIV+ children. A hundred and forty (140) enamel blocks were randomly assigned to six groups: biofilm formed by C. albicans (Group 1); mixed biofilm formed by $\mathrm{C}$. albicans and C. tropicalis (Group 2); mixed biofilm formed by $\mathrm{C}$. albicans and C. parapsilosis (Group 3); mixed biofilm formed by C. albicans, C. parapsilosis and C. glabrata (Group 4); biofilm formed by C. albicans ATCC (Group 5) and medium without Candida (Group 6). Enamel blocks from each group were removed on days 3, 5, 8 and 15 after biofilm formation to evaluate the TMH and images of enamel were analyzed by PLM. The quantity of $\mathrm{Ca}^{2+}$ released, from Groups 1 and 6, was determined using an Atomic Absorption Spectrophotometer. The SPSS program was used for statistical analysis and the significance level was 5\%. Results: TMH showed a gradual reduction in enamel hardness $(p<0.05)$ from the $1^{\text {st }}$ to $15^{\text {th }}$ day, but mainly five days after biofilm formation in all groups. The PLM showed superficial lesions indicating an increase in porosity. C. albicans caused the release of $\mathrm{Ca}^{2+}$ into suspension during biofilm formation. Conclusion: Candida species from dental biofilm of HIV+ children can cause demineralization of primary enamel in vitro.

Keywords: Candida albicans. Dental caries. HIV infections. Child. Hardness.
Corresponding address: Gloria Fernanda Barbosa de Araújo Castro Rua Araguaia, 994, bl. 2, apt 304 - Freguesia Jacarepaguá - Rio de Janeiro - RJ 22.745-270 - Brazil e-mail: gfbacastro@yahoo.com.br
${ }^{1}$ Universidade Federal do Rio de Janeiro, Faculdade de Odontologia, Departamento de Odontopediatria e Ortodontia, Rio de Janeiro, RJ, Brasil.

2Universidade de Brasília, Faculdade de Odontologia, Departamento de Cariologia, Brasília, DF, Brasil.

${ }^{3}$ Universidade Federal Fluminense, Faculdade de Odontologia, Departamento de Clínica e Odontopediatria, Niterói, RJ, Brasil.

${ }^{4}$ Universidade Federal do Rio de Janeiro, Instituto de Microbiologia Paulo de Góes, Departamento de Microbiologia, Rio de Janeiro, RJ, Brasil. 


\section{Introduction}

The most common oral lesion of HIV infected children is candidiasis ${ }^{25}$ and the major etiologic agent of this oral lesion is C. albicans ${ }^{26}$. However, various studies have evidenced the presence of other species with pathogenic features such as C. tropicalis, C. parapsilosis, C. glabrata, C. guillermondii and C. dubliniensis 22,24 . Studies in the literature have associated the presence of Candida spp. in the oral cavity with the development of caries lesions 7,30 . Nikawa, et al.15 (1994) suggested the possibility that biofilms colonized by $\mathrm{C}$. albicans have increased cariogenicity, because this yeast can produce lactic acid through the fermentation of carbohydrates and degenerate the dental hydroxyapatite structure. Also, C. albicans can produce enzymes with collagenolytic activity (aspartic proteases) and dental collagen hydrolysate ${ }^{17}$.

Children infected with HIV tend to present a higher prevalence of caries compared with noninfected children ${ }^{7,19}$. The most probable hypotheses that support this are: the ingestion of a hypercaloric diet, a high sucrose content in medicines ${ }^{20}$, low immunosuppression ${ }^{4}$ and unsatisfactory oral hygiene ${ }^{23}$. Considering these possible roles of Candida in the development of caries and the fact that HIV infected children present a high prevalence of these fungi and caries lesions, further studies are needed. Also, other possible factors involved in the beginning and development of caries disease in these patients should be investigated.

In this study, we hypothesized that, in vitro, Candida spp. isolated from the dental biofilm of HIV infected $(\mathrm{HIV}+)$ children is able to demineralize primary molar enamel. Thus, strains of $C$. albicans and non-albicans from the dental biofilm of HIV+ children were isolated and identified. The in vitro capacity of these Candida spp. samples to demineralize primary molar enamel was analyzed by Transversal Microhardness (TMH) and Polarized Light Microscopy (PLM) and furthermore the quantity of calcium ion $\left(\mathrm{Ca}^{2+}\right)$ released from the enamel was determined.

\section{Material and methods}

\section{Microorganisms}

The Candida spp. samples were isolated from the thick supragingival biofilm ${ }^{23}$ on the dental surfaces of fifty (50) patients of both genders, aged between 3 and 12 years old with definitive diagnosis for HIV infection according to the CDC criteria ${ }^{6}$. The HIV+ children were selected by convenience over an 8-month period. These children attended the Pediatric AIDS Outpatient Clinic at the Pediatric Hospital of the Federal University of Rio de Janeiro (IPPMG-UFRJ) on a regular basis and were assisted by the School of Dentistry of the same institution. Children who had been under antifungal therapy in the least three months or used topic oropharyngeal antimicrobial drugs were not included in the study. Other medical data were obtained from their medical records.

To collect the biofilm, standard dental curettes were rubbed against the easiest accessed dental surface that allowed relative isolation of saliva. The material collected was transferred to Eppendorffs tubes containing $1 \mathrm{~mL}$ of $\mathrm{NaCl}-0.85 \%$, and then kept under refrigeration until analysis. For the analysis, $100 \mathrm{~mL}$ of these suspensions was seeded onto Petri plates containing CHROMagar Candida ${ }^{\circledR}$ medium and incubated at $37^{\circ} \mathrm{C}$ for 72 hours ${ }^{18}$. Colonies were analyzed by using biochemical tests of fermentation and sugar assimilation (API 20C System, Biomerieux, Marcy L'Étoile, Lyon, France). Also, green colonies were inoculated in Sabouraud dextrose agar to screen their ability to grow at $45^{\circ} \mathrm{C}$ in 48 hours and thus differentiate between $\mathrm{C}$. albicans and $\mathrm{C}$. dubliniensis ${ }^{8}$.

This study was approved by the Ethics Committee of the UFRJ and informed consent form was obtained from the caregivers of the children.

\section{Preparation of specimens of human primary teeth}

Forty (40) sound primary molars without any visible alteration (stereoscopic microscope, 40x, Astro Optics Division, Montpelier, Vermont, USA) were selected. They were cut by a double sided diamond disc, forming 140 enamel blocks ( $5 \times 5 \times 2 \mathrm{~mm})$. After cleaning ${ }^{5}$ all the areas were protected by nail varnish (two layers, with 24 hours for drying each layer) except for a circular area with $6.25 \mathrm{~mm}^{2}$ in the center of each block. This area was exposed to Candida biofilms, while the protected area served as its own control since it was not exposed to the biofilm.

\section{Biofilm formation}

After quantification and identification of Candida spp., we observed that 45 patients presented positive growth of only $\mathrm{C}$. albicans in the supragingival biofilm; 
three presented positive growth of C. albicans and C. parapsilosis simultaneously; one, positive growth of both $\mathrm{C}$. albicans and $\mathrm{C}$. tropicalis; and one, positive growth of C. albicans, C. parapsilosis and C. glabrata simultaneously. Thus, five (5) strains of C. albicans were randomly selected from five (5) different patients, who had just presented this species. Also, isolates of $\mathrm{C}$. albicans and non-albicans pertaining to patients who simultaneously presented isolates of: C. albicans + C. parapsilosis; C. albicans + C. tropicalis; and C. albicans + C. parapsilosis + C. glabrata (one isolate of each species) were selected. One reference isolate of C. albicans (ATCC 24433) was used.

The 140 blocks were sterilized ${ }^{1}$ and fixed in 24well plates containing YCB-agar culture medium (Yeast Carbon Base, Difco, Trenton, New Jersey, USA), with $1 \%$ BSA (Bovine Serum Albumin) ${ }^{8}$. Ten 24-well plates containing 14 dental blocks each were divided into six groups: Group 1 - enamel exposed to C. albicans biofilm ( $n=70$ blocks; five plates); Group 2 - mixed biofilm formed by C. albicans and C. tropicalis ( $n=14$; one plate); Group 3 - mixed biofilm formed by $C$. albicans and C. parapsilosis $(n=14$; one plate); Group 4 - mixed biofilm formed by $\mathrm{C}$. albicans, C. parapsilosis and C. glabrata $(n=14$; one plate); Group 5 - C. albicans biofilm (ATCC 24433) ( $n=14$; one plate); Group 6 (control group) - absence of Candida biofilm ( $n=14$; one plate). Standard cell suspensions containing $10^{5}$ yeasts $/ \mathrm{mL}$ sowed in YCB medium supplemented with BSA $1 \%$ under mixing for 48 hours at $37^{\circ} \mathrm{C}$ were inoculated in each well, except for the control. The biofilm formation occurred after incubation at $37^{\circ} \mathrm{C}$.

Two (2) dental blocks were removed from each plate after the $1^{\text {st }}, 3^{\text {rd }}, 5^{\text {th }}, 8^{\text {th }}, 10^{\text {th }}, 12^{\text {th }}$ and $15^{\text {th }}$ day, and inserted in Falcon tubes containing $5 \mathrm{~mL}$ of $\mathrm{NaCl}(0.85 \%)$ and vortexed for one minute. Biofilm cell viability was assessed through the Trypan blue exclusion test. All blocks were sterilized, cleaned using a soft brush with water and pumice paste and then stored in a pot containing cotton soaked in $\mathrm{NaCl}$ for future analysis.

\section{Transversal Microhardness (TMH)}

The enamel TMH was measured using a Knoop indenter with a 50 gram load for 15 seconds ${ }^{8,10}$. The blocks were longitudinally sectioned through the equatorial region by a precision sectioning cutter (Isomet, Buehler, Lake Bluff, Illinois, USA) with a double sided diamond disc, forming two enamel blocks. Only one half of each block was built-in acrylic resin and its enamel surface was polished with mesh sandpaper (1000 grit, 1200 grit and 2400 grit) (3M, Sumaré, São Paulo, Brazil) for 10 minutes. Then, a polishing machine with felt discs (Arotec Ind. \& Com. Ltda; São Paulo, São Paulo, Brazil) and abrasive alumina (1 and $0.3 \mu \mathrm{m}$; South Bay Technology Inc.; San Clemente, California, USA) were used until the surfaces were plain and smooth. Indentations were made at distances of $12.5,25,37.5,50,62.5,75$, $87.5,100,112.5,125,137.5,150 \mu \mathrm{m}$ from the external surface into the dentin-enamel junction $(D E J)^{28}$. All the previously patterned indentations had been made in the enamel areas exposed to the biofilm as well as in those protected areas.

\section{Polarized Light Microscopy (PLM) analysis}

For the qualitative analysis, 14 enamel fragments remaining from the blocks used in Group 1 were selected. They were examined through a $100 x$ magnification PLM under crossed Nichols, with quartz accessories. The fragments were prepared by hand using increasing grades of water sandpaper (1000 grit, 1200 grit and 2400 grit). After that, they were polished with felt polishing paste until a $100 \mu \mathrm{m}$ longitudinal section was observed. This measure was obtained by using a digital micrometer.

\section{Determination of $\mathrm{Ca}^{2+}$ released}

To determine the amount of calcium ion $\left(\mathrm{Ca}^{2+}\right)$ released from the blocks, an Atomic Absorption Spectrophotometer (air flame/nitrous oxide) (ContrAA 300, Analytik Jena, Uberlingen, Germany) equipped with a calcium-specific hollow cathode lamp was used at the following operating conditions: lamp current 3 $\mathrm{mA}$; fuel, acetylene/nitrous oxide flame; wavelength, $423 \mathrm{~nm}$. Briefly, $1 \mathrm{~mL}$ of the suspension from one plate (selected randomly) of Group 1 (C. albicans, $n=14$ ) and from the plate of Group 6 (control group, $n=14$ ) was collected from each well on the $1^{\text {st }}, 3^{\text {rd }}, 5^{\text {th }}, 8^{\text {th }}, 10^{\text {th }}$, $12^{\text {th }}$ and $15^{\text {th }}$ day. After centrifugation (3000 xg, for 3 minutes, at $4^{\circ} \mathrm{C}$ ) the supernatant portions were stored in plastic tubes with screw caps containing $250 \mu \mathrm{L}$ of nitric acid $65 \%\left(\mathrm{HNO}_{3}\right)$ and kept under refrigeration until analysis. For the analysis, $200 \mu \mathrm{L}$ of the sample was put into $3 \mathrm{~mL}$ of $53 \mathrm{mM} \mathrm{La}\left(\mathrm{NO}_{3}\right)_{3}$ and then 50 $\mathrm{mM} \mathrm{HCl}$ was added ${ }^{27}$. Standard solutions containing $10,20,40$ and $80-\mu \mathrm{g} / \mathrm{mL}$ calcium were prepared. The 
readings of the calcium ion release were compared with a standard curve obtained from readings of the standard solutions. Hence, the calcium release was calculated on the $1^{\text {st }}, 3^{\text {rd }}, 5^{\text {th }}, 8^{\text {th }}, 10^{\text {th }}, 12^{\text {th }}$ and $15^{\text {th }}$ day.

\section{Statistical analysis}

In order to determine the $\mathrm{TMH}$, the sum of the indentation values was made, followed by the arithmetic mean. Data were analyzed by SPSS Statistics Program 20. Parametric statistical tests were used for correlations and the significance level was $5 \%$ $(p<0.05)$. The means of TMH, on the different days, in each group, were compared using the Analysis of Variance (ANOVA). Comparisons between the TMH values of the exposed and nonexposed areas were made for Group 1 using the T-Student test. For the other groups, only a descriptive analysis was made due to the small sample size. Also, the results of PLM and $\mathrm{Ca}^{2+}$ releases were descriptively analyzed.

\section{Results}

For the in vitro experiments, from the 45 patients that presented positive growth only for $\mathrm{C}$. albicans in the supragingival biofilm, five (5) C albicans isolates were randomly selected from five different patients, resulting in a sample of 70 dental blocks for Group 1 (14 blocks for each isolate). However, the number of patients that presented positive growth of $\mathrm{C}$. albicans and other species simultaneously were very few. Thus, one isolate of $\mathrm{C}$. albicans and one of non-albicans, pertaining to patients who simultaneously presented these isolates, were selected [Group 2: C. albicans + C. parapsilosis; Group 3: C. albicans + C. tropicalis; Group 4: C. albicans + C. parapsilosis + C. glabrata (one isolate of each specie)], resulting in 14 dental blocks for each group.

The results of TMH are shown in Table 1. A gradual decrease $(p<0.05$; ANOVA) of the TMH values in areas exposed to biofilm was observed over the period (from the $1^{\text {st }}$ to $15^{\text {th }}$ day) in all groups exposed to Candida biofilm (Groups 1 to 5). In nonexposed areas this variation was not significant for these groups. In Group 6 (no Candida biofilm formation) both exposed and nonexposed areas did not present any significant difference in $\mathrm{TMH}$ values.

The TMH values of exposed and nonexposed areas were daily compared only in the group with $\mathrm{C}$. albicans biofilm (Group 1). There was no difference on the

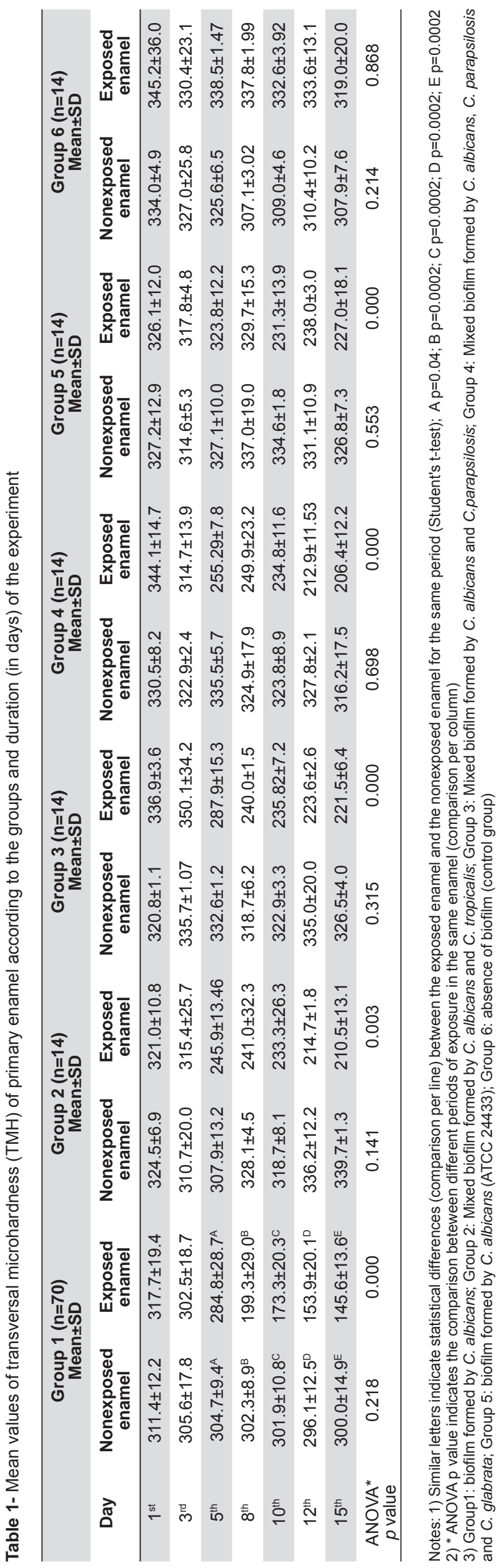

J Appl Oral Sci. 56 2017;25(1):53-60 


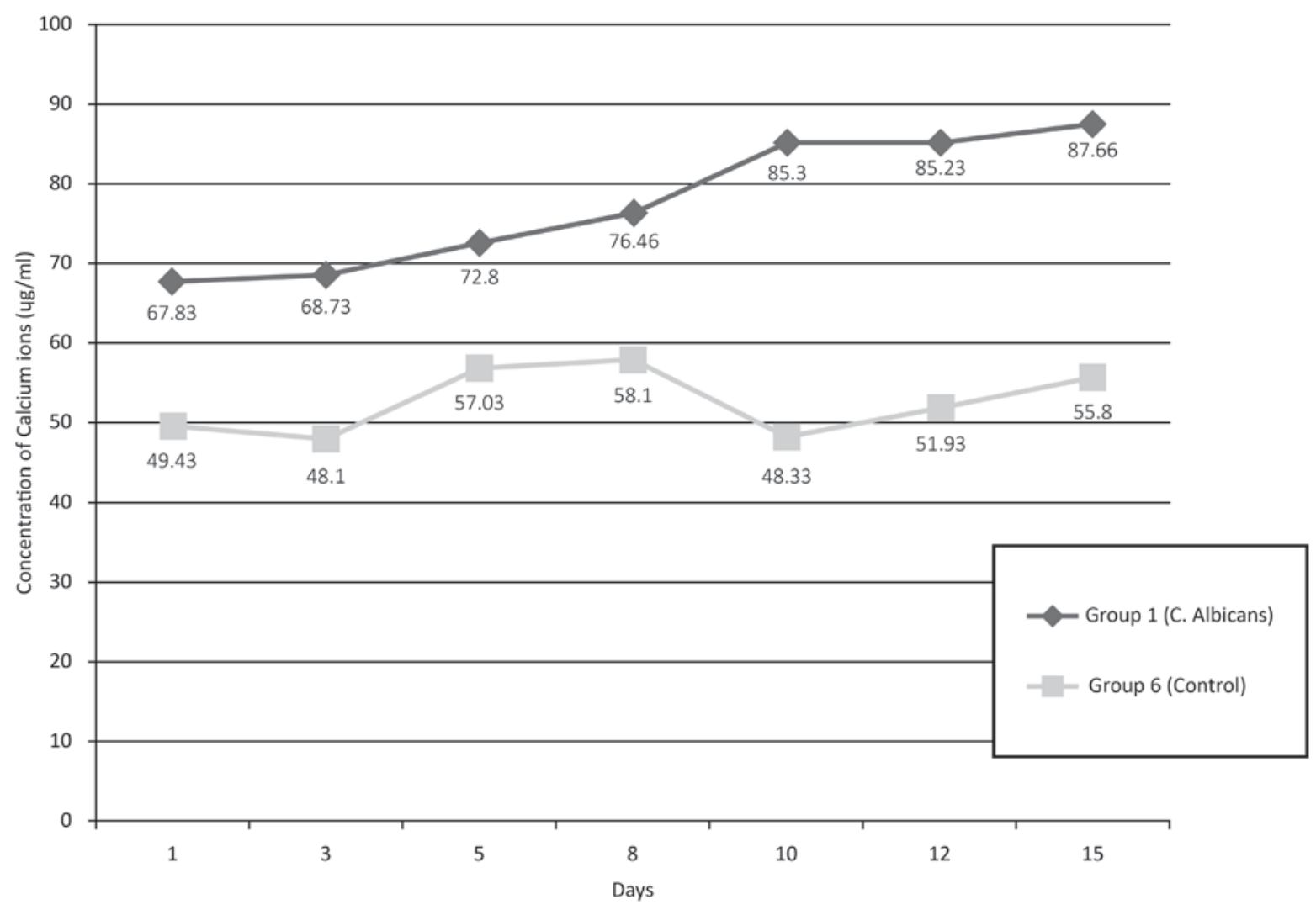

Figure 1- Polarized light microscopy (PLM) images of the enamel blocks from Group 1 (C. albicans biofilm), according to the different periods of exposure. Images A, C, E and G are the areas of enamel exposed to biofilm of $C$. albicans on $1^{\text {st }}, 5^{\text {th }}, 8^{\text {th }}$ and $15^{\text {th }}$ day respectively. Images $\mathrm{B}, \mathrm{D}, \mathrm{F}$ and $\mathrm{H}$ represent the respective controls (areas not exposed to biofilm)

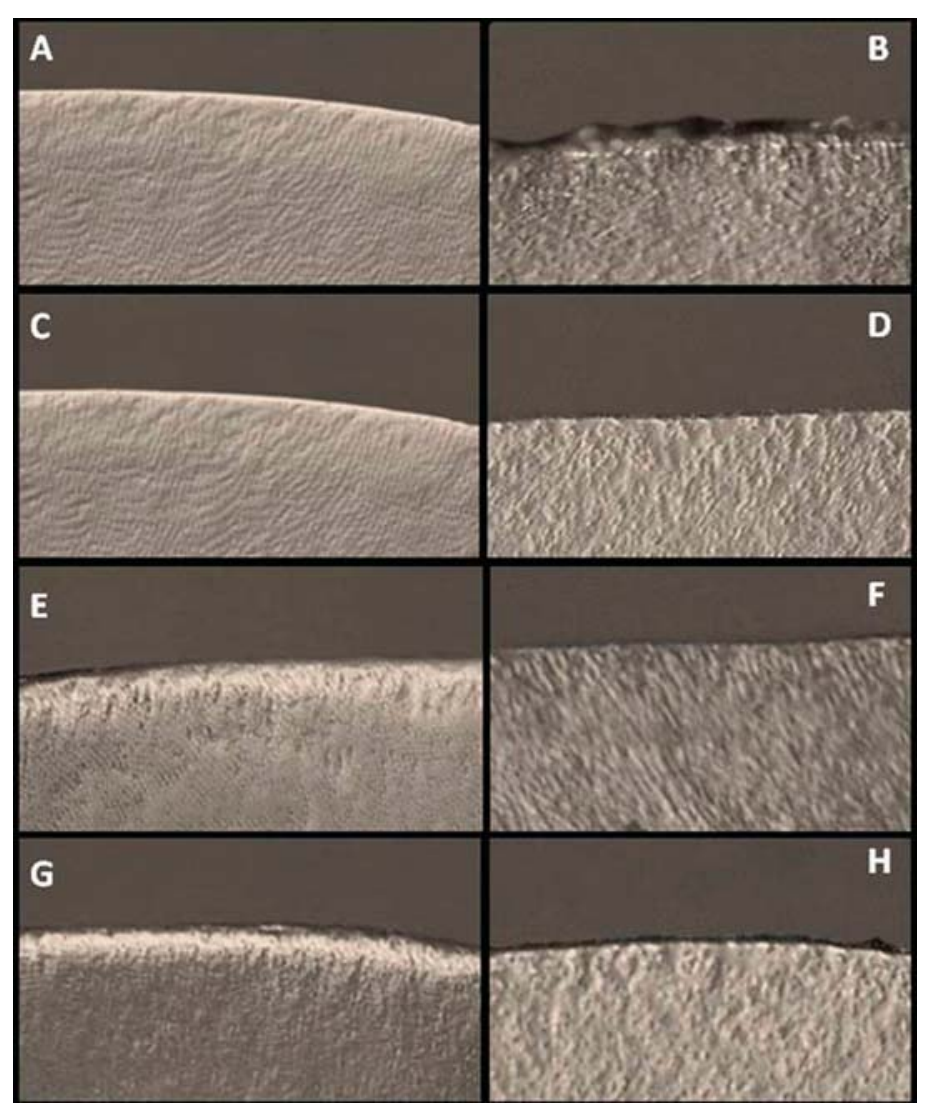

Figure 2- Release of calcium ions $(\mu \mathrm{g} / \mathrm{mL})$ during $C$. albicans biofilm formation, according to the different periods of exposure. $A=c o n t r o l$, $\mathrm{B}=1^{\text {st }}$ day, $\mathrm{C}=3^{\text {rd }}$ day, $\mathrm{D}=5^{\text {th }}$ day, $\mathrm{E}=8^{\text {th }}$ day, $\mathrm{F}=10^{\text {th }}$ day, $\mathrm{G}=12^{\text {th }}$ day and $\mathrm{H}=15^{\text {th }}$ day 
$1^{\text {st }}$ and $3^{\text {rd }}$ day, but from the $5^{\text {th }}$ day on, a significant difference ( $p<0.05$; Student's t-test) was observed. In groups with mixed biofilm (Groups 2, 3 and 4), the results show a similar behavior in Groups 2, 3 and 4. In Group 5 the decrease in the TMH values may be observed as of the $10^{\text {th }}$ day, however, in Group 6, TMH values were similar throughout the experiment (Table 1). However, statistical test for these comparisons in groups with mixed biofilm were not carried out because of the reduced sample size in each day, in these groups.

Mineral losses observed using PLM showed that enamel areas exposed to $\mathrm{C}$. albicans biofilm presented a superficial zone with negative birefringence (double refraction) and lesions in the sub-surface zone with positive birefringence (double refraction), indicating an increase in porosity. This porosity increase along the enamel-dentin junction, increased during the experiment. In Figure 1, the images 2A, 2C, 2E and 2G show the enamel areas exposed to $C$. albicans during the $1^{\text {st }}, 5^{\text {th }}, 8^{\text {th }}$ and $15^{\text {th }}$ days respectively. The images $2 \mathrm{~B}, 2 \mathrm{D}, 2 \mathrm{~F}$ and $2 \mathrm{H}$ show their respective controls (protected areas).

The quantity of $\mathrm{Ca}^{2+}$ ions released into the medium during the Candida albicans biofilm forming experiment is shown in Figure 2. There was an increase in the quantity of $\mathrm{Ca}^{2+}$ ions released over the days of the experiment in Group 1 (C. albicans biofilm).

\section{Discussion}

Nikawa, et al. ${ }^{16}$ (2003) observed that C. albicans presents cariogenic potential and has the ability to dissolve hydroxyapatite crystals in large proportions. According to these authors, this species has collagenolytic activity, sticking to the collagen in the regular and denatured forms by different mechanisms, which could contribute to the persistence of the yeast on the dissolved hydroxyapatite surface ${ }^{14,21}$. Our results show that Candida spp., in mixed biofilm or not, has a potential to cause enamel demineralization in vitro, since the microhardness analysis of enamel showed a significant decrease along the experiment. Also, we noted that in the $\mathrm{C}$. albicans biofilm group, from the $5^{\text {th }}$ day on, the TMH values of exposed and nonexposed areas were different. We hypothesized that this may have been due to the fact that yeasts present a more intense metabolism after the $5^{\text {th }}$ day or this result could be associated with an increase of lactic acid production along the days, as an accumulative effect. In addition, a recent study from our group showed that mature biofilm of $\mathrm{C}$. albicans can be observed as of the $5^{\text {th }}$ day, under the same experimental conditions (data not shown).

Secreted aspartyl proteinases (Saps) are among the most important virulence factors of Candida spp. Their relationship to the development of candidiasis by adhesion to human tissues, degradation of extracellular matrix and other important proteins associated with human defense is well known. Recently, Li, et al. ${ }^{13}$ (2014) demonstrated the role of Candida albicans-Saps in severe early childhood caries. The authors observed by enzymatic activity that the species isolated from the biofilm of children with severe early childhood caries were statically higher producers of Saps than the C. albicans isolates of caries free group. Moreover, different members of the Sap family might be differentially expressed depending on the environment and host conditions. The gene expression levels of Sap1-5 are the predominant protease genes expressed in C. albicans from dental biofilm and Sap1 may play an important role in the development of severe early childhood caries ${ }^{13}$. Additionally, Brighenti, et al. $^{3}$ (2014) also observed caries associated with other virulence factors (production of acid, extracellular polysaccharides, proteins and metabolic activity) of C. albicans biofilm isolated from the saliva of patients with sickle-cell anemia. These authors demonstrated that $\mathrm{C}$. albicans biofilms from patients with sickle-cell anemia presented a greater caries-associated virulence than isolates from healthy children.

A limitation of our study was the small sample size of the groups exposed to mixed biofilm formed by $C$. albicans and non-albicans, which did not allow a quantitative analysis between TMH values of the exposed versus nonexposed areas. Therefore, these results must be discussed with caution. On the other hand, our descriptive analysis shows that the values of the $\mathrm{TMH}$ of blocks exposed to a mixed biofilm formed by $C$. albicans and non-albicans species presented a profile similar to those exposed only to $C$. albicans, but with a smaller decrease. Some competition between the Candida species may be occurring in the mixed biofilm that could decrease the activity of the $C$. albicans species in the system ${ }^{29}$. Future investigations of the demineralization profile of each Candida nonalbicans isolated could help to explain this phenomenon of a reduced demineralization in a mixed biofilm. 
On the other hand, although some results were descriptively analyzed, the comparability of our results with those in the literature shows some consistency ${ }^{8,21,30}$. Although this in vitro study shows a confirmatory result, few studies in the literature show the in vitro demineralization potential of Candida spp. biofilm and the real role of these yeasts in caries disease processes. Besides, there are studies that have already demonstrated a potential synergism among Candida albicans and Streptococcus mutans ${ }^{9,12}$. However, we did not consider S. mutans in our experiments in order to only compare the demineralization potentials of Candida albicans and non-albicans, since our objective is to understand the real demineralization profile of these yeasts. Additionally, the importance of S. mutans in the development of caries lesions is already known in the current literature. However, novel investigations regarding the synergistic demineralization potential of a mixed biofilm of Candida spp., isolated from oral cavity of HIV infected children, and S. mutans are been initiated to better understand the biological significance.

The small variation of microhardness values on the enamel nonexposed to Candida spp. biofilm (Groups 1 to 5), as well as the whole of Group 6 (control group), shows that the $\mathrm{pH}$ variation of the culture medium was not able to cause any significant mineral loss. Moreover, our results showing the loss of calcium ions by atomic force absorption and the polarized light images also reflected the changes found in microhardness of the enamel exposed to $C$ albicans biofilm over the days of the experiment. However, on some days, in the control group (Group $6)$, the calcium concentration in the suspension reduced instead of increasing gradually. This could be explained by the fact that the quantification of calcium release was performed in only one isolate per day, randomly selected, and the isolate used may have been one of those that causes less mineral loss.

Although various studies have already shown the demineralization ability of Candida species isolated from other oral cavity sites ${ }^{11,30}$, the literature is very scarce in studies about strains from HIV-infected children, who have high caries prevalence. In parallel, these yeasts have characteristics that are strain dependent principally when participating in a biofilm environment. Arzmi, et al. ${ }^{2}$ (2015) showed that different strains of $\mathrm{C}$. albicans present a distinct profile of coaggregation with $A$. naeslundii and $S$. mutans in a biofilm environment. These data reinforce the importance of this study.

\section{Conclusions}

1. Our study confirms the capacity of Candida spp. isolates from dental biofilm of HIV infected children to cause in vitro enamel demineralization.

2. Confirming the cariogenic potential of yeasts and elucidating the exact participation of Candida spp. in the development of caries will contribute to caries disease control in HIV infected patients.

\section{Acknowledgements}

This study was supported by FAPERJ - Rio de Janeiro Research Foundation, Brazil.

\section{References}

1- Amaechi BT, Higham SM, Edgar WM. Efficacy of sterilization methods and their effect on enamel demineralisation. Caries Res. 1998;32:441-6.

2- Arzmi MH, Dashper S, Catmull D, Cirillo N, Reynolds EC, McCullough $M$ Coaggregation of Candida albicans, Actinomyces naeslundii and Streptococcus mutans is Candida albicans strain dependent. FEMS Yeast Res. 2015;15:fov038.

3- Brighenti FL, Medeiros AC, Matos BM, Ribeiro ZE, Koga-Ito CY. Evaluation of caries-associated virulence of biofilms from Candida albicans isolated from saliva of pediatric patients with sickle-cell anemia. J Appl Oral Sci. 2014;22:484-9.

4- Castro GF, Souza IP, Lopes S, Stashenko P, Teles RP. Salivary IgA to cariogenic bacteria in HIV-positive children and its correlation with caries prevalence and levels of cariogenic microorganisms. Oral Microbiol Immunol. 2004;19:281-8

5- Ccahuana-Vásquez RA, Tabchoury CPM, Tenuta LM, Del Bel Cury AA, Vale GC, Cury JA. Effect of frequency of sucrose exposure on dental biofilm composition and enamel demineralization in the presence of fluoride. Caries Res. 2007;41:9-15.

6- Center for Disease Control and Prevention - CDC. Revised classification system for human immunodeficiency virus infection in children less than 13 years of age. MMWR. 1994;43:1-10.

7- Cerqueira DF, Portela MB, Pomarico L, Soares RM, Souza IP, Castro GF. Examining dentinal carious lesions as a predisposing factor for the oral prevalence of Candida ssp in HIV-infected children. J Dent Child (Chic). 2007;74:98-103.

8- Charone S, Portela MB, Chagas MS, Araújo Soares RM, Araújo Castro GF. Biofilm of Candida albicans from oral cavity of an HIV-infected child: challenge on enamel microhardness. Oral Surg Oral Med Oral Pathol Oral Radiol. 2013;115:500-4

9- Falsetta ML, Klein MI, Colonne PM, Scott-Anne K, Gregoire S, Pa $\mathrm{CH}$, et al. Symbiotic relationship between Streptococcus mutans and Candida albicans synergizes virulence of plaque biofilms in vivo. Infect Immun. 2014;82:1968-81.

10- Featherstone JD, ten Cate JM, Shariati M, Arends J. Comparison of artificial caries-like lesions by quantitative microradiography and microhardness profiles. Caries Res. 1983;17:385-91. 
11- Kneist S, Borutta A, Sigusch BW, Nietzsche S, Küpper H, Kostrzewa $M$, et al. First-time isolation of Candida dubliniensis from plaque and carious dentine of primary teeth. Eur Arch Paediatr Dent. 2015;16:36570 .

12- Koo H, Bowen WH. Candida albicans and Streptococcus mutans: a potential synergistic alliance to cause virulent tooth decay in children. Future Microbiol. 2014;9:1295-7

13- Li W, Yu D, Gao S, Lin J, Chen Z, Zhao W. Role of Candida albicanssecreted aspartyl proteinases (Saps) in severe early childhood caries. Int J Mol Sci. 2014;15:10766-79.

14- Nikawa $H$, Hamada $T$, Yamashiro $H$, Murata $H$, Subiwahjudi $A$. The effect of saliva or serum on Streptococcus mutans and Candida albicans colonization of hydroxyapatite beads. J Dent. 1998;26:31-7. 15- Nikawa H, Yamamoto T, Hayashi S, Nikawa Y, Hamada T. Growth and/or acid production of Candida albicans on soft lining materials in vitro. J Oral Rehabil. 1994;21:585-94.

16- Nikawa $\mathrm{H}$, Yamashiro $\mathrm{H}$, Makihira S. In vitro cariogenic potential of Candida albicans. Mycoses. 2003;46:471-8.

17- Nishimura M, Nikawa H, Yamashiro H, Hamada T, Embery G. Cellassociated collagen activity by Candida albicans. Mycopathologia. 2002; $153: 125-8$

18- Odds FC, Bernaerts R. CHROMagar Candida, a new differential isolation medium for presumptive identification of clinically important Candida species. J Clin Microbiol. 1994;32:1923-9.

19- Oliveira CA, Tannure PN, Souza IP, Maia LC, Portela MB, Castro GF. Is dental caries experience increased in HIV-infected children and adolescents? A meta-analysis. Acta Odontol Scand. 2015;12:1-7. 20- Pomarico L, Czauski G, Portela MB, Souza IP, Kneipp LF, Araújo Soares RM, et al. Cariogenic and erosive potential of the medication used by HIV-infected children: $\mathrm{pH}$ and sugar concentration. Community Dent Health. 2008;25:170-2.

21- Portela MB, Chagas MS, Cerqueira DF, Souza IP, Souto-Padrón T, Araújo Soares RM, et al. Differential collagenolytic activity of Candida albicans isolated from oral mucosa and dentinal carious lesions of HIV-infected children. Oral Surg Oral Med Oral Pathol Oral Radiol. 2012;113:378-83.
22- Portela MB, Souza IP, Costa EM, Alviano CS, Soares RM, Santos AL. Differential recovery of Candida species from subgingival sites in human immunodeficiency virus-positive and healthy children from Rio de Janeiro, Brazil. J Clin Microbiol. 2004;42:5925-7.

23- Ribeiro AA, Portela M, Souza IP. Relation between biofilm, caries activity and gingivitis in HIV+ children. Braz Oral Res. 2002;16:144-50. 24- Richardson MD. Changing patterns and trends in systemic fungal infections. J Antimicrob Chemother. 2005;56:Suppl 1:i5-i11.

25- Santos LC, Castro GF, Souza IP, Oliveira RH. Oral manifestations related to immunosuppression degree in HIV-positive children. Braz Dent J. 2001;12:135-8.

26- Starr JR, White TC, Leroux BG, Luis HS, Bernardo M, Leitao J, et al. Persistence of oral Candida albicans carriage in healthy Portuguese schoolchildren followed for 3 years. Oral Microbiol Immunol. 2002;17:304-10.

27- Szabó B, Majoros L, Papp-Falusi E, Szabó Z, Szabó J, Márton I, et al. Studies on the possible aetiological role of different Candida species in pathogenesis of dentine caries by monitoring the calcium release from tooth particles. Acta Microbiol Immunol Hung. 2014;61:11-7. 28- Takatsuka T, Exterkate RA, ten Cate JM. Effects of Isomalt on enamel de- and remineralization, a combined in vitro $\mathrm{pH}$-cycling model and in situ study. Clin Oral Invest. 2008;12:173-7.

29- Thein ZM, Samaranayake YH, Samaranayake LP. Characteristics of dual species Candida biofilms on denture acrylic surfaces. Archs Oral Biol. 2007;23:1200-8

30- Udayalaxmi J, Shenoy N. Comparison between biofilm production, phospholipase and haemolytic activity of different species of Candida isolated from dental caries lesions in children. J Clin Diagn Res. 2016;10:DC21-3. 